\title{
Fulsome conundrum: solving the nation's shortage of photonics personnel with education
}

\section{Steven Moore}

Steven D. Moore, "Fulsome conundrum: solving the nation's shortage of photonics personnel with education," Proc. SPIE 4588, Seventh International Conference on Education and Training in Optics and Photonics, (28 May 2002); doi: $10.1117 / 12.468748$

SPIE Event: Education and Training in Optics and Photonics 2001, 2001, Singapore, Singapore 


\title{
The Fulsome Conundrum: Solving the nation's shortage of photonics personnel with education
}

\author{
Steven D. Moore \\ Center for Image Processing in Education
}

\begin{abstract}
Nationwide, photonics technicians are in short supply. Even with the recent downturn in the nation's economy, thousands of technicians are needed by traditional optics manufacturing companies, telecommunications providers, defense contractors, and other industries that rely on photonics technologies. Though many reasons have been offered to explain why the shortage has occurred, the lack of technicians remains a fulsome conundrum. This paper addresses ten hypotheses commonly cited to explain the shortage of qualified technicians. Then, the evidence that supports or disconfirms the hypotheses is explored. Direct and indirect actions are identified that photonics industries could take to help alleviate the shortage of trained personnel. Direct actions include (1) collaborating with appropriate experts to study the problem in more detail; (2) conducting outreach programs with local schools and informal education centers; and (3) helping produce K-12 educational materials that integrate photonics concepts into all areas of the school curriculum. Indirect actions include (1) collaborating in building educational systems that encourage young people to pursue technical careers; (2) becoming part of the K-college educational enterprise; (3) lobbying federal and state governmental agencies; and (4) engaging in partnerships.
\end{abstract}

Keywords: Education, workforce development, technical workforce, photonics education

\section{THE FULSOME CONUNDRUM}

During a recent visit to an optics manufacturer, the head of a community college program that awards associate's degrees in optical systems technology watched as a pizza deliveryman was hired to be a manufacturing technician for the company. The young man had arrived at the optics firm a few minutes earlier to deliver a pizza for a local fast food chain. After briefly quizzing the man about his current salary and career expectations, the owner of the optics firm offered the deliveryman nearly double his current salary of seven dollars an hour. The deliveryman took the job.

This story underscores the desperate shortage facing our nation's photonics industries. Too few trained technicians are chasing an abundance of available positions. Too highly trained and costly personnel—e.g., engineers—are filling technical roles. Two-year programs that provide technical personnel to photonics manufacturers simply cannot graduate sufficient personnel to satisfy the demands of the marketplace. Students who graduate with an associate's degree in photonics technology enjoy the luxury of multiple opportunities. Students with as little as one or two semesters of photonics coursework under their belts are often hired off by photonics industries. Many such personnel fail to return to school because of the difficulty of timing work schedules with school schedules. The result is that optics manufacturing suffers. Many personnel working on 
photonics manufacturing floors simply do not have basic technical competencies in optical concepts, mathematics, and science.

Community college programs prepare many technicians who work for photonics industries. These colleges offer a spectrum of programs for new and returning students, including certificates of proficiency, terminal associate's degrees, and two-plus-two programs leading to undergraduate degrees. A core problem facing nearly all community college programs is a shortage of students with sufficient skills and interest to succeed in photonics careers. Many hypotheses have been cited to explain the shortage of qualified and interested students. These hypotheses are listed below.

1. Young people in the United States have a distaste for science, think that scientists are "nerdy" or weird, and thus stay away from technical careers.

2. High school students are not sufficiently prepared in science and mathematics to succeed in college-level coursework that is foundational to photonics careers.

3. In comparison to students in other developed nations, American students are poorly prepared in science and mathematics. Because today's students are tomorrow's engineers, technicians, and technicians, the United States is losing its competitive edge in the photonics field.

4. The teachers who are preparing today's cohort of high school students have poor credentials in science and mathematics.

5. High school students and their advisors underestimate the amount of mathematics and science preparation needed for success in technical courses at the undergraduate level.

6. Teachers are being held accountable for their students' performance in meeting state and federal standards for science and mathematics education. Because no standards directly address photonics concepts, teachers do not cover material relevant to the industry.

7. Families are poorly involved in their children's education, leading to poor performance in science and mathematics courses.

8. American students, burdened by poor mathematics and science instructional materials, are handicapped in their pursuit of coursework that provides the foundation for technical careers.

9. Females and members of disadvantaged minority groups reject science, mathematics, and technical careers at an early age.

10. Students at all levels are unaware of the contribution of photonics to everyday life and the careers that are available in the industry.

This paper examines the evidence that confirms or disconfirms each hypothesis.

\section{THE EVIDENCE}

To explore whether the hypotheses can be accepted or rejected, recent studies conducted by the U. S. Department of Education, the American Association for the Advancement of Science, and the 
American Institute of Physics were reviewed. The review uncovered evidence relevant to all but one of the hypotheses.

1. Young people in the United States have a distaste for science, think that scientists are "nerdy" or weird, and thus stay away from technical careers.

Results from recent nationwide surveys of eighth and twelfth graders indicate that liking science is a 50:50 proposition (Figure 1). ${ }^{1}$ One could argue equally well that this statistic is good news or bad news for those individuals who wish to promote technical careers. On one hand, fifty percent of students in the eighth and twelfth grades reported that they like science. Presumably, these students would look favorably upon the image of scientists in society and be open to pursuing a technical career. On the other hand, an equal number of students dislike the scientific enterprise. Assuming that students who dislike science dislike scientists as well, nearly a majority of young people would choose role models other than scientists in forming life choices. Similar though less encouraging statistics are apparent for mathematics. Less than a majority of eighth and twelfth graders express a liking for mathematics. Encouragement can be derived from a "science is boring" item. Less than $30 \%$ of eighth and twelfth graders expressed agreement with that statement. Apparently, though science may not be to their liking, it is at least interesting.

Figure 1: Students' Attitudes towards

Mathemathics and Science

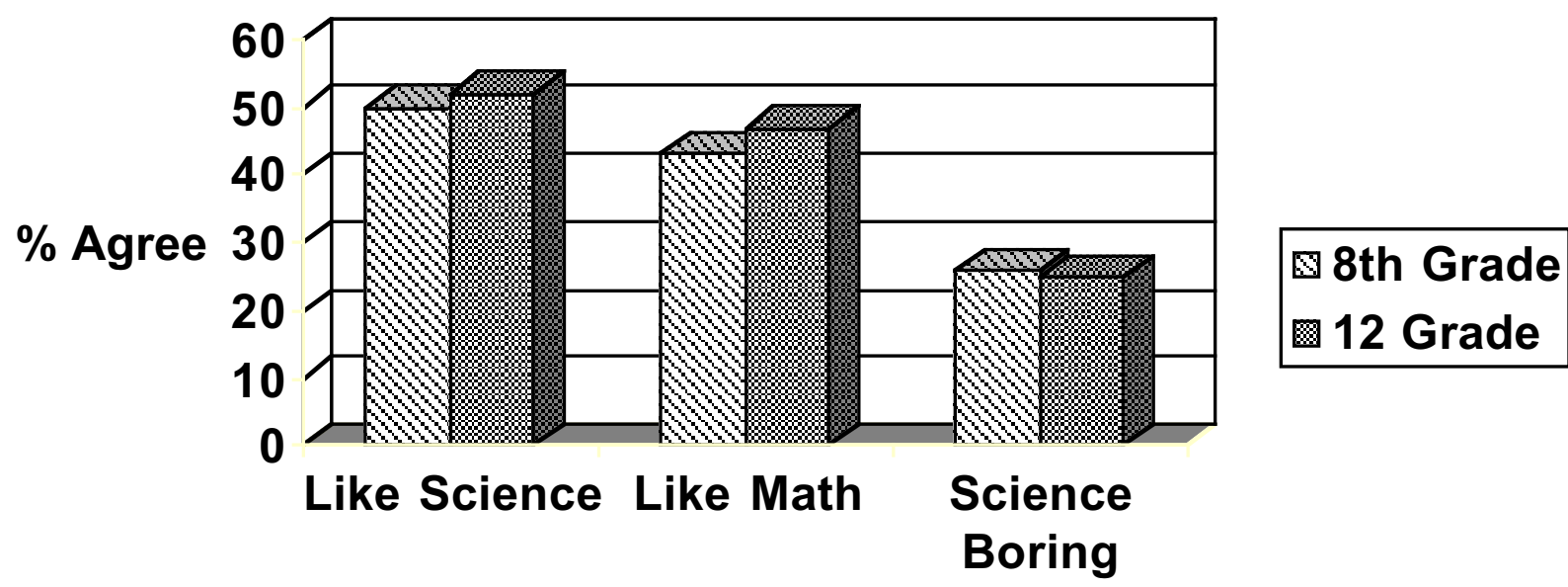

Disturbing is the decrease in students' perceived science and mathematical competence that occurs between grades eight and twelve (Figure 2). ${ }^{1}$ For some reason, students lose confidence in their science and mathematical abilities during their high school years. 
Figure 2: Students'

Self Confidence

in Math and Science

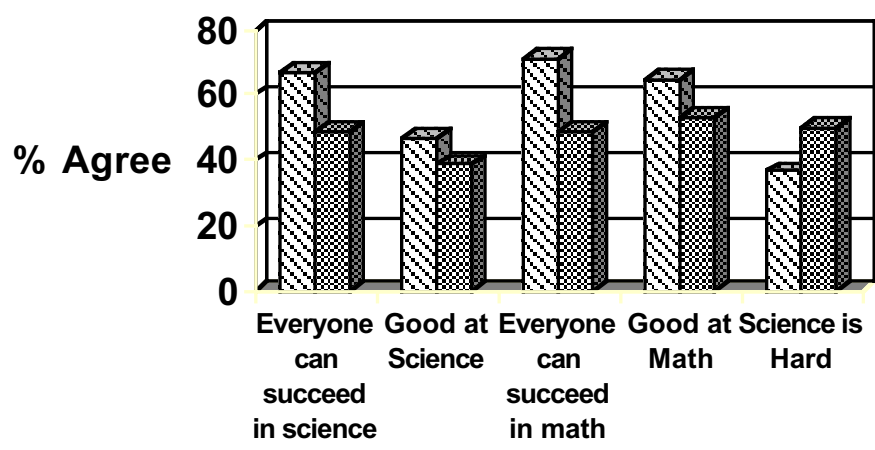

\section{$₫$ 8th Grade}

12 Grade

2. High school students are not sufficiently prepared in science and mathematics to succeed in college level coursework that is foundational to photonics careers.

Self-reported enrollment in key science and mathematics courses indicates that students are taking foundational courses for careers in photonics (Figure 3). ${ }^{1}$ More than $70 \%$ of twelfth grade students report having taken chemistry, $40 \%$ report having taken physics, $90 \%$ algebra I, $80 \%$ algebra II, $85 \%$ geometry, $25 \%$ trigonometry, and $18 \%$ calculus. These statistics must be regarded with caution, however. Self-reports by middle and high school students may inflate the content and categories of courses they have taken in schools. Actual school records would be a more reliable indicator of enrollment trends.

Figure 3: Self-Reported

Enrollment of 12th Graders in

Key Math and Science Classes

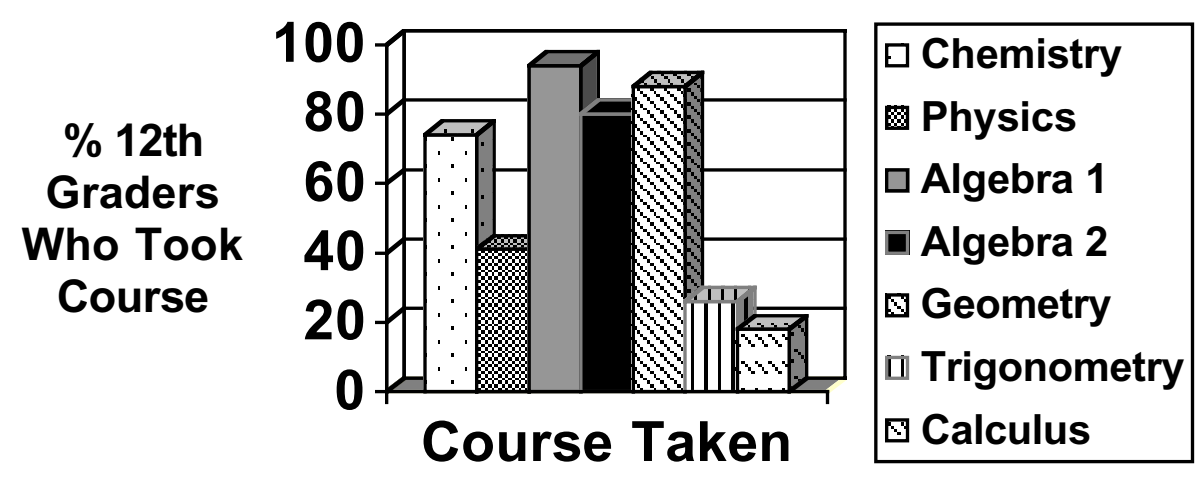


Trends in physics enrollment in the twelfth grade show a rebounding after a dip in the 1960 's - 1980's. ${ }^{2}$ After reaching a low of $17 \%$ in 1987, physics enrollment for seniors grew until it exceeded $25 \%$ in the late 1990 's.

\section{American students are poorly prepared in science and mathematics and thus cannot succeed in photonics careers.}

According to the Third International Mathematics and Science Study (TIMSS), ${ }^{3} 8$ th graders in the United States scored slightly above the international average in science and math achievement. Although this result sounds encouraging, it represents an overall decline in performance: Students ranked higher against their international peers in the fourth grade (in 1995) than they did in the eighth grade (in 1999). The TIMSS results also indicated that students in the United States spent less time than their international peers studying and doing homework in science and math. Although these results do not indicate that American students will necessarily fail in technical studies, they do imply that the United States may be losing a competitive edge in workforce development. Solace can be gained from the fact that mathematics scores for elementary-level American students steadily improved during the 1990s. ${ }^{1}$

\section{The teachers who are preparing today's cohort of high school students have poor credentials in science and mathematics.}

This hypothesis appears to have limited empirical support. According to an American Institute of Physics sponsored study, the physics credentials of high school teachers are not as bad as typically portrayed. ${ }^{4}$ About one third of physics teachers have at least a minor in physics. Over half of the high school physics teachers without physics degrees have spent a large fraction of their careers teaching courses in the subject. More than a third of these teachers describe themselves as specialists in physics.

More support for the notion of poorly prepared science and mathematics educators is found at the elementary levels. For example, low percentages of math-specialized educators are found in the elementary grades (Figure 4). ${ }^{5}$ Although this result is to be expected because of the generalist nature of elementary education, it does reveal that the nation may be shortchanging itself in establishing a foundation for a technically oriented workforce. Nevertheless, results from the TIMSS study and National Assessment of Educational Progress (NAEP) survey of students self-perceived confidence indicate that elementary level educators are doing a good job of not only conveying mathematical and scientific concepts, but also building students' confidence in those subjects. Problems seem to occur at the high school level, where content-specific credentials are more common. 
Figure 4: Percentage of 4th and 8th Grade

Educators with Mathematics Credentials

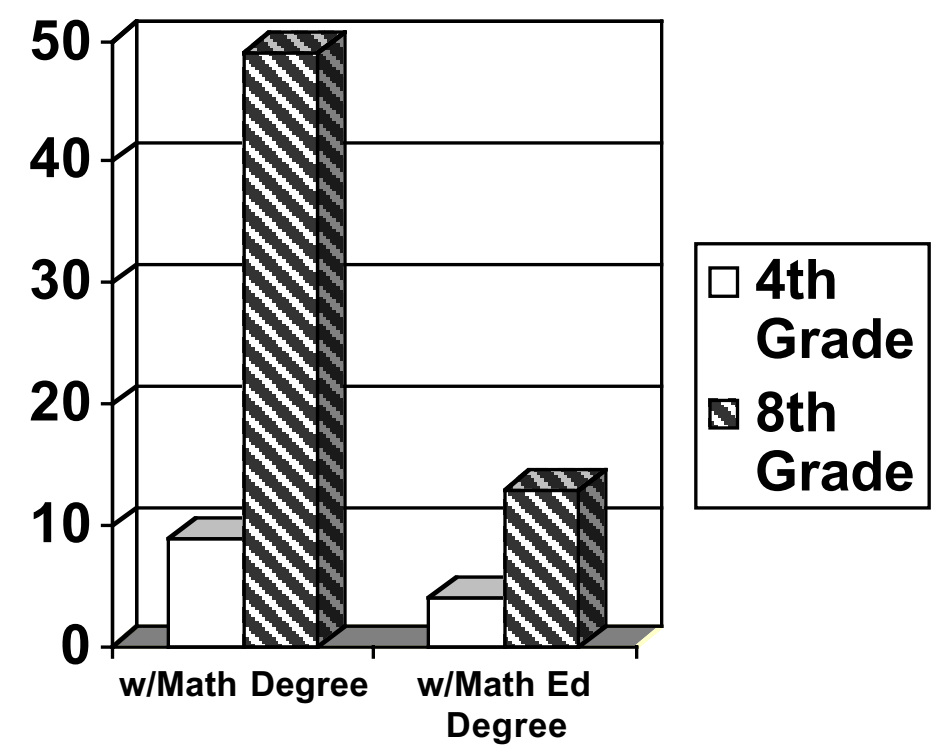

5. High school students and their advisors underestimate the amount of mathematics and science preparation needed for success in technical courses at the undergraduate level.

According to a 1993 report from the National Science Foundation, ${ }^{6}$

"One explanation of why so few students are taking advanced courses in science and math may be the low levels of students who think these courses are necessary for their planned careers. Relatively few students seem to understand the relationship between advanced math and science courses and careers in science, engineering, or the health professions."

Anecdotal evidence from a number of informal sources indicates that this statement is true. Teachers report that students seem to have little understanding of the kinds of science and mathematics courses needed for careers in technical disciplines. Unfortunately, according to teachers informally interviewed for this paper, many school guidance counselors have little more understanding about what it takes to succeed in science and mathematics than their students. Consequently, students have little guidance in making choices that will help them succeed in higher-level technical courses.

6. Teachers are being held accountable for their students' performance in meeting state and federal standards for science and mathematics education. Because no standards directly address photonics concepts, teachers do not cover material relevant to the industry.

It is true that the National Science Education Standards ${ }^{7}$ fail to directly address many concepts relevant to the photonics industries. Nevertheless, many standards could be fulfilled with photonics- 
based instructional activities that integrate with traditional subjects such as biology, Earth science, chemistry, mathematics, and physics. Examples of content areas that could be treated by photonicsbased learning are offered below (Table 1).

Table 1: National Science Education Standards Relevant to Photonics Industries.

\begin{tabular}{|c|c|c|c|}
\hline \multicolumn{4}{|c|}{ National Science Education Standards, Content Standards: Grades 9-12 } \\
\hline $\begin{array}{l}\text { Unifying Concepts } \\
\text { and Principles }\end{array}$ & Science as Inquiry & Physical Science & Life Science \\
\hline $\begin{array}{l}\text { - Systems, order, } \\
\text { and organization } \\
\text { - Evidence models } \\
\text { and explanation } \\
\text { - Change, } \\
\text { constancy, and } \\
\text { measurement } \\
\text { - Form and function }\end{array}$ & $\begin{array}{l}\text { - Abilities necessary } \\
\text { to do scientific } \\
\text { inquiry } \\
\text { - Understandings } \\
\text { about scientific } \\
\text { inquiry }\end{array}$ & $\begin{array}{ll}\text { - } & \text { Structure of atoms } \\
\text { - } & \text { Structure and } \\
& \text { properties of } \\
& \text { matter } \\
\text { - } & \text { Chemical reactions } \\
\text { - } & \text { Interactions of } \\
& \text { energy and matter }\end{array}$ & $\begin{array}{l}\text { - Matter, energy, } \\
\text { and organization } \\
\text { in living systems }\end{array}$ \\
\hline $\begin{array}{l}\text { Earth and Space } \\
\text { Science }\end{array}$ & $\begin{array}{l}\text { Science and } \\
\text { Technology }\end{array}$ & $\begin{array}{l}\text { Science in Personal } \\
\text { and Social } \\
\text { Perspectives }\end{array}$ & $\begin{array}{l}\text { History and Nature of } \\
\text { Science }\end{array}$ \\
\hline $\begin{array}{l}\text { - Energy in the } \\
\text { Earth system }\end{array}$ & 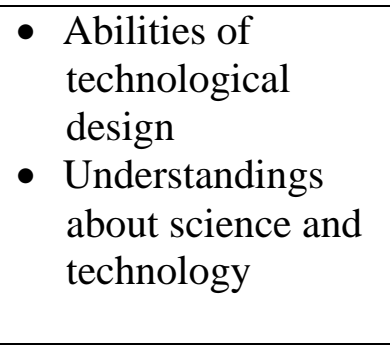 & $\begin{array}{ll}\text { - } & \text { Natural resources } \\
\text { - Environmental } \\
\text { quality } \\
\text { - Science and } \\
\text { technology in } \\
\text { local, national, and } \\
\text { global challenges } \\
\end{array}$ & 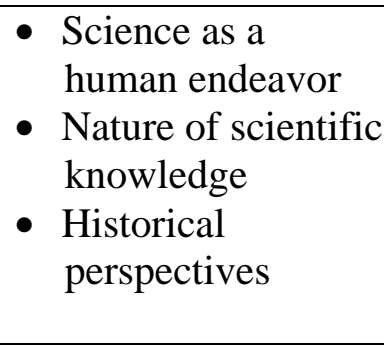 \\
\hline
\end{tabular}

Photonics is an inherently mathematical discipline. Accordingly, opportunities abound to create photonics-based instructional materials that integrate with national mathematics education standards such at these grades 9-12 standards from the Principles and Standards for School Mathematics of the National Council for Teachers of Mathematics: ${ }^{8}$

- Represent and analyze mathematical situations and structures using algebraic symbols.

- Analyze characteristics and properties of two- and three-dimensional geometric shapes and develop mathematical arguments about geometric relationships.

- Understand measurable attributes of objects and the units, systems, and processes of measurement.

\section{Family structures have broken down in the United States, leading to poor performance in science and mathematics courses.}

Empirical evidence, at least superficially, tends to validate this claim. Statistically speaking, students from intact families (with both biological parents present) tend to perform better in school and express fewer behavioral challenges than students in other living arrangements (Figure 5). ${ }^{9}$ 
Whether such performance and behavioral issues extend to science and mathematics education is not revealed in the data.

Figure 5: Family structure versus performance in school (from Nord and Light 2001) ${ }^{9}$

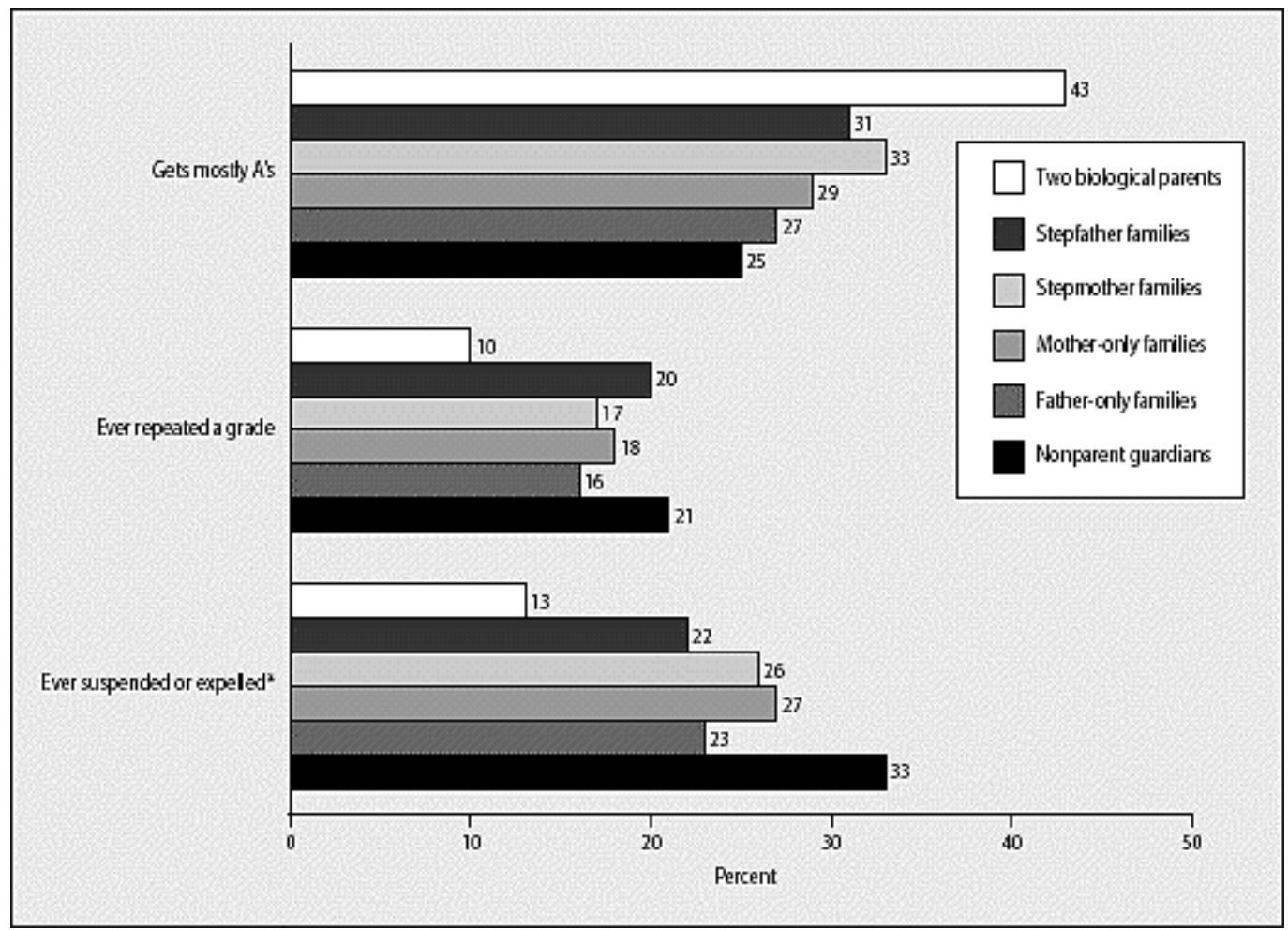

8. American students, burdened by poor mathematics and science instructional materials, are handicapped in their pursuit of coursework that provides the foundation for technical careers.

This hypothesis appears to be supported by the evidence, particularly at the middle grades. Not one of the widely used science textbooks for middle school was rated satisfactory by Project 2061, a long-term science, mathematics, and technology education reform initiative of the American Association for the Advancement of Science. ${ }^{10}$ Similarly, the Project 2061 group identified only a few excellent middle-grades mathematics textbooks. None were popular commercial textbooks. Problems cited for the middle school mathematics textbooks were inconsistent and weak coverage of conceptual benchmarks in mathematics; little development in the sophistication of mathematical ideas from grades six to eight; and unsatisfactory support for providing a purpose for learning mathematics, taking account of student ideas, and promoting student thinking. ${ }^{11}$

9. Females reject science, mathematics, and technical careers at an early age.

This hypothesis is based on the observation that enrollment and staffing in undergraduate engineering programs is heavily weighted towards males. Mixed results are found with respect to this hypothesis. Girls' enrollment in physics classes has been increasing, but girls do not tend to take upper level physics classes in high school. ${ }^{2}$ Boy's mathematics scores are slightly higher in high school, but science scores are about the same. ${ }^{1}$ These results indicate that females perform 
similarly to males in science and mathematics courses. However, social and psychological factors not reflected in the scores may be driving young females away from technical careers.

10. Students at all levels are unaware of the contribution of photonics to everyday life and the careers that are available in the industry.

No data was uncovered to support or refute this claim. Presumably, because photonics is an enabling technology that underlies many commonly used technologies, students may not be familiar with the photonics industry and thus are unaware of the career possibilities that exist in the field.

\section{SOLUTIONS}

A conundrum implies a riddle that is difficult or impossible to solve. Fortunately, this brief review hints that the photonics industry has many opportunities and resources available to help solve this conundrum. It can work towards a solution by influencing young people's awareness of the field and students' preparedness to enter into technical fields. These opportunities fall into two categories: What can be influenced directly by the photonics industry and what can only be influenced indirectly (Table 2).

Table 2: Educational Issues that can be Influenced Directly and Indirectly by the Photonics Industry

\begin{tabular}{|l|l|}
\hline \multicolumn{1}{|c|}{ Can Be Influenced Directly: } & \multicolumn{1}{|c|}{ Can Be Influenced Indirectly: } \\
\hline Students' attitudes toward science and mathematics & Preparation of teachers \\
\hline $\begin{array}{l}\text { Students' perception of photonics as an industry } \\
\text { and as a career choice }\end{array}$ & $\begin{array}{l}\text { Perceived science and mathematics } \\
\text { abilities at high school level }\end{array}$ \\
\hline Students' perception of scientists & $\begin{array}{l}\text { Educational performance of US students in } \\
\text { science and mathematics }\end{array}$ \\
\hline $\begin{array}{l}\text { Students' understanding of what it takes to be a } \\
\text { technician, scientist, or engineer }\end{array}$ & $\begin{array}{l}\text { Family involvement in students' lives and } \\
\text { their education }\end{array}$ \\
\hline $\begin{array}{l}\text { Creation of excellent instructional materials and } \\
\text { educational opportunities }\end{array}$ & $\begin{array}{l}\text { Creation of educational standards that } \\
\text { address the needs of the photonics industry }\end{array}$ \\
\hline
\end{tabular}

\subsection{Direct Solutions}

Probably one of the greatest deficits uncovered while conducting research for this paper was the lack of publicly available information about students' career interests. Similarly, no information was found that addressed students' awareness of the photonics industry and the career opportunities that exist in the field. This deficit could be easily overcome with a survey of middle and high school students that probed current career plans, perceptions of the photonics industry, and awareness of career opportunities in photonics-related fields.

Using the survey results as a foundation from which to build outreach efforts, the photonics industry could enhance and expand existing programs that integrate scientists, engineers, and technicians 
into schools and other educational institutions. Outreach programs provide excellent opportunities for photonics professionals to mentor teachers, serve as role models for students, and even provide instruction to classrooms.

A key to fostering lasting change in the classroom is to provide educators with easy-to-implement instructional materials that are tied to national standards and integrate with existing curricular structure. A brief search on the Internet reveals that dozens of optics-related activities and multimedia demonstrations have been created for educators' use and student consumption. Unfortunately, most such materials have limited instructional support and do not integrate well with subjects such as biology, chemistry, mathematics, and social studies. Educators would welcome well-crafted materials that teach important science, mathematics, and humanities content with photonics. The photonics industry could underwrite this effort.

One key to successful implementation of professional outreach programs may be to start early. Children are capable of learning more than previously thought. Mathematics and science is usually absent in early childhood education. Early childhood teachers and caregivers are often ill prepared to incorporate appropriate science, mathematics, or technology experiences into children's lives. ${ }^{12}$ Photonics professionals providing special optics education sessions at elementary schools and even in pre-school environments could do much to build awareness for the industry, foster interest in the power of light, and spark excitement about science in general. A good example of one such thrust is the Dr. Mike Nofziger's Nursery School Optics website posted at http://www.optics.arizona.edu/K12 _Outreach/K-12_Nursery_School/Nursery_School_Optics.htm.

\subsection{Indirect Solutions}

Indirectly, the photonics industry can work to change the environment that influences students' educational outcomes and choices. It can accomplish this task by becoming part of the educational enterprise rather than simply an end user of the system's products. Today's technical workplace is much different than the industrial workplace of 50- or even just 20-years ago. Unfortunately, the skills and processes still taught in many of the nation's schools prepare young people to work in business environments that existed nearly a century ago. Photonics professionals and industry organizations can work with federal, state, and local agencies to influence the structure of school curricula, the choice of concepts and processes taught in the schools, and the selection of educators who prepare tomorrow's technical workforce.

Although the photonics industry can do little to alter the structure of families in the United States, it can include families in outreach efforts. Outreach programs that include families in photonics-based educational events, job fairs, and even tours of design and manufacturing facilities could help build awareness for the industry, as well as aid parents in understanding the preparation needed to enter into technical careers.

Photonics professionals could also serve as lobbyists motivated to change the way instruction is provided to students and the goals that guide such instruction. By creating partnerships with textbook publishers and curriculum committees in local school districts, photonics professionals could influence the content of science instruction and lobby for the kinds of hands-on explorations of photonics concepts that excite students' interest in the field. Concerned professionals and industry organizations could work to change state and national standards for science and 
mathematics education. Such standards could easily be modified to include concepts relevant to photonics research and practice.

\section{CONCLUSION}

Industrial corporations typically fear investing heavily in K-12 educational systems because the return on investment is difficult or impossible to track. Few businesses are willing to invest $\$ 500$ or more per student in a local middle school to raise awareness about photonics careers in general. Few of the students reached by such outreach efforts will likely become photonics technicians, engineers, or scientists. As a result, the industry's focus remains on recruitment at transition points: high school and undergraduate seniors. However, as the evidence in this paper has revealed, most potential technical workers are lost before the traditional transition points occur. The solution to the fulsome conundrum is clear. The photonics industry must intercede early and effectively if it is to become more than a frustrated end-user. It will need to invest heavily in direct and indirect solutions to the problem. And, it will need to have faith that today's investment will reap substantial returns for our nation and its future as a technological leader.

\section{ACKNOWLEDGEMENTS}

Funding for the research conducted for this paper was provided, in part, by the National Science Foundation under grant number DUE 0053262 (Consortium for Optics and Imaging Education).

\section{REFERENCES}

1. NCES. National Assessment of Educational Progress, National Center for Education Statistics, U.S. Department of Education. Web page accessed at http://nces.ed.gov/nationsreportcard/. 2001.

2. Neuschatz, M. and M. McFarling. Maintaining Momentum: High school physics for a new millenium, American Institute of Physics. Web page accessed at http://www.aip.org/statistics/trends/reports/hsreport.pdf. 2001.

3. NCES. Third International Mathematics and Science Study-Repeat, Web page accessed at http://nces.ed.gov/timss/. 2001.

4. Neuschatz, M. and M. McFarling, "Background and professional qualifications of highschool physics teachers," The Physics Teacher, 38(February): pp. 98-104. 2000.

5. NSF. Science and Engineering Indicators 2000, National Science Foundation. Web page accessed at http://www.nsf.gov/sbe/srs/seind00/access/c5/c5s2.htm\#c5s216. 2001.

6. NSF. Science \& Engineering Indicators - 1993, National Science Foundation. Web page accessed at http://www.nsf.gov/sbe/srs/seind93/chap1/doc/1c793.htm. 2001.

7. NRC, National science education standards. National Research Council/National Academy of Sciences, Washington, DC. 1996.

8. NCTM. Principles and standards for school mathematics, National Council for Teachers of Mathematics. Web page accessed at http://www.nctm.org/standards/. 2001. 
9. Nord, C.W. and J. West, Fathers' and mothers' involvement in their children's schools by family type and resident status (NCES 2001-032). National Center for Educational Statistics: Washington DC 2001.

10. AAAS. Heavy Books Light on Learning: Not One Middle Grades Science Text Rated Satisfactory By AAAS's Project 2061, American Academy for the Advancement of Science. Web page accessed at http://www.project2061.org/newsinfo/press/r1092899.htm. 2001.

11. AAAS. Middle Grades Mathematics Textbooks: A benchmarks-based evaluation, American Association for the Advancement of Science. Web page accessed at http://www.project2061.org/matheval/default.htm. 2001.

12. AAAS. Dialogue on Early Childhood Science, Mathematics, and Technology Education, American Association for the Advancement of Science. Web page accessed at http://www.project2061.org/newsinfo/earlychild/default.htm. 2001. 